\title{
Effect of Local Anesthesia with 1:100,000 Epinephrine on Glycemic Level of Type II Diabetic Patients Undergoing Oral Surgery
}

\author{
Muhammad Tariq Khan ${ }^{1}$, Muhammad Ilyas ${ }^{2}$, Salman Khan ${ }^{3}$, Jawad Ahmad Kundi \\ Shahid $^{5}$, Fariha Kifayat ${ }^{6}$
}

\begin{abstract}
Background: The rate of type II diabetic patients is increasing and results in oral manifestations. The oral surgery needs extraordinary measures in these patients.

Objective: To assess the effect of anesthetic agent with 1:100,000 epinephrine and without epinephrine in the blood glucose level of diabetic patients.

Material and Methods: This was a randomized study of 60 patients having type 2 diabetes mellitus who were undergoing tooth extraction. The study was double blind. 30-70years aged patients were selected. Blood glucose level was monitored 15 minutes before giving local anesthesia and after 20 minutes of the injection. ANOVA was used for comparison between groups.

Results: No significant difference was seen in glycemic level using local anesthesia with 1:100,000 epinephrine ( $p=0.345)$. There was slight decrease noted in the blood glucose level of both groups.

Conclusion: The use of $2 \%$ local anesthesia with 1:100,000epinephrine didn't cause hyperglycemia in diabetic patients.

Keywords: Diabetes Mellitus, Local Anesthesia, Epinephrine, Tooth Extraction, Lidocaine.
\end{abstract}

This article may be cited as: Khan MT, llyas M, Khan S, Kundi JA, Shahid, Kifayat F. Effect of Local Anesthesia with 1:100,000 Epinephrine on Glycemic Level of Type II Diabetic Patients Undergoing Oral Surgery. J Saidu Med Coll Swat 2021;11(4):181-4.DOI:https://doi.org/10.52206/jsmc.2021.11.4.674

\section{INTRODUCTION}

The most common endocrine metabolic disorder is Diabetes Mellitus (DM). The rate of Type 2 Diabetic patients is increasing with approximately $85-90 \%$ is diagnosed with type 2 diabetes. Microvascular abnormalities in persistent hyperglycemic leads to oral manifestations as well as serious damage to other target organs. ${ }^{1-4}$ In diabetic patients, oralsurgery needs extraordinary safety measures for example, the use of safe and effective anesthestic solution and stress control. During psychological stress catecholamines (endogenous) are secreted that may results in unwanted increase in blood glucose level, blood pressure and heart rate. ${ }^{5,6}$ The vasoconstrictors to

1. Associate Professor, Head of Department Dentistry/ Maxillofacial Surgery Department, Saidu Medical College \& Saidu Group of Teaching Hospitals, Swat. drkhnsw01@gmail.com.

2. Incharge Oral and Dental Surgery Department, District Headquarter Hospital, Ghallanay, District Mohmand.

3. MDS Resident, Department of Oral and Maxillofacial Surgery, Sardar Begum Dental College, Peshawar.

4. Professor \& Head of Department, Oral and Maxillofacial Surgery, Sardar Begum Dental College, Peshawar.

5. MSc Resident, Department of Endodontics,

Sardar Begum Dental College, Peshawar.

6. FCPS Resident, Department of Oral and Maxillofacial Surgery, Sardar Begum Dental College, Peshawar.

Correspondence: Dr. Muhammad Ilyas

Incharge Oral and Dental Surgery Department,

District Headquarter Hospital, Ghallanay,

District Mohmand.

Email: ilyas_khan526@yahoo.com

Received: August 24 $4^{\text {th }}, 2020$ Accepted: February 08 $8^{\text {th }}, 2021$ local anesthesia provide unquestionable advantage for example, decrease toxic effect by delaying Absorption, reduce local bleeding and longer lasting anesthesia. ${ }^{7,8}$

There is controversy exist with regard to hyperglycemic control in the use of local anesthesia in type 2 diabetes mellitus. Tily and Thomson compared the effect of local anesthesia with adrenaline on blood glucose level in healthy and diabetic patients and found no significant difference plasma glucose level. ${ }^{9}$ Meechan reported a significant increase in the blood glucose level after 10 and 20 minutes following injection of local anesthetic with epinephrine. ${ }^{10}$ Naveed in another study didn't observe any significant changes in the blood glucose level in healthy as well as diabetic patients. ${ }^{11}$ Siddiq et al ${ }^{12}$ compared the effect of local enesthesia with and without adrenaline on diabetic patients who underwent tooth extraction and found no significant difference in the blood glucose level in both groups. Adelusi in one of the study found that there was modest increase in blood glucose level while using local anesthesia with adrenaline in patients undergoing tooth extraction but the increase was not statistically significant. ${ }^{13}$ Some authors recommend epinephrine free local anesthesia while others concluded that local anesthesia with epinephrine is not contraindicated in the type 2 diabetes mellitus. ${ }^{9-15}$ Though many studies have been conducted with inconclusive results on blood glucose level of diabetic patients. This study aimed to determine the differences in blood glucose level in type 2 diabetic patients 
during tooth extraction using local anesthesia with plain $2 \%$ lidocaine versus $2 \%$ lidocaine with 1:100,000 epinephrine.

\section{MATERIALAND METHODS}

This was a randomized study which was carried out in the Maxillofacial Surgery Department, Saidu Medical College \& Saidu Group of Teaching Hospitals, Swat from $1^{\text {st }}$ January 2018 to $31^{\text {st }}$ December 2018. The study was approved by the Head of Department of Oral \& Maxillofacial Surgery and ethical committee of Saidu Medical College \& Saidu Group of Teaching Hospitals, Swat. The patients enrolled were type 2 diabetes mellitus (type of diabetes when your body's cells resist the normal effect of insulin, which is to drive glucose in the blood into the inside of the cells as a result the blood glucose level increases) ${ }^{16}$ posterior tooth extraction. The patients were in the age group of 30-70 years. Patients having pregnancy, underlying systemic diseases like cardiovascular, liver or renal disease, uncontrolled major depression, any other psychiatric disorders and those receiving any other medications other than oral hypoglycemic were excluded from the study. An informed consent was taken from those patients who were included in this study. Blood glucose level was checked by using Accu-Check Active blood glucose meter (Roche-FDA approved) 15 minutes prior to giving local anesthesia and after 20 minutes of injection. Two cartridges $(1.8 \mathrm{~mL})$ were used. This was random blood sugar (RBS) level as the patients undergoing teeth extraction was advised to take breakfast before the procedure. The study was double blind. The oral surgeon who carried procedure didn't know the blood glucose level and the type of anesthesia given. The procedure was carried out by the post graduate residents of the Department under supervision of Head of the Department. The patients were divided into two groups:

Group A: Those receiving local anesthesia without epinephrine.

Group B: Those receiving local anesthesia with 1:100,000 epinephrine.

Descriptive statistics like mean and standard deviations were applied for age, length of diabetes and sugar level. Frequency and percentage was applied for gender. Analysis of variance (ANOVA) was performed to compare the groups. A p value $=0.05$ was considered significant and level of confidence interval was kept at $95 \%$.

\section{RESULTS}

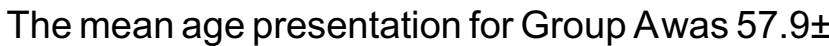
7.9 years and for Group B was $56.0 \pm 6.9$ years as shown in table 1 . Male were predominant in both groups as shown in the figure 1 . Table 1 is also showing the mean value of random blood sugar before and after anesthesia in Group Aand B. The mean random blood sugar after anesthesia is decreasing in both groups. The length of duration of diabetes is approximately the same in both groups. ANOVA showed that there was no significant difference in random blood sugar that was treated using local anesthesia with $1: 100,000$ epinephrine $(p=0.345)$.

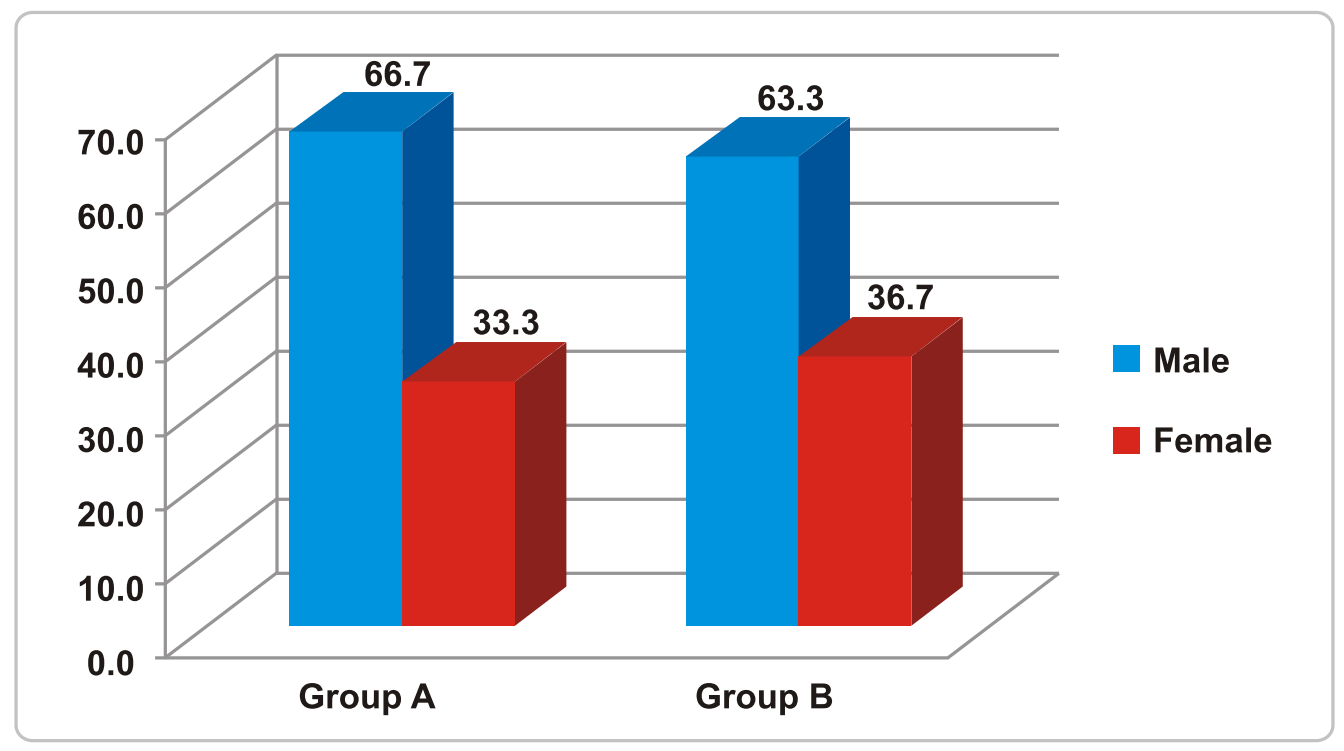

Fig 1. Gender percentage amongst groups. 
Table.1. Age, length of diabetes, random blood sugar before and after anesthesia in each group.

\begin{tabular}{|lll|}
\hline \multicolumn{1}{|c|}{ Characteristics } & \multicolumn{2}{c|}{$\begin{array}{c}\text { Groups } \\
\text { (Mean \& Standard Deviation) }\end{array}$} \\
\hline & $\begin{array}{l}\text { Local anesthesia } \\
\text { without Epinephrine } \\
\text { (Group A) }\end{array}$ & $\begin{array}{l}\text { Local anesthesia } \\
\text { with Epinephrine } \\
1: 100,000 \\
\text { (Group b) }\end{array}$ \\
\hline Age(years) & & $56.0 \pm 6.9$ \\
\hline Length of diabetes(years) & $57.9 \pm 7.9$ & $13.5 \pm 8.6$ \\
\hline Before anesthesia(mg/dl) & $13.9 \pm 8.9$ & $208.70 \pm 23.5$ \\
\hline After anesthesia(mg/dl) & $206.47 \pm 22.2$ & $199.60 \pm 23.9$ \\
\hline
\end{tabular}

\section{DISCUSSION}

This study revealed the differences that occurred in sugar level in type 2 diabetic patients who underwent oral surgery while using $2 \%$ lidocaine without epinephrine and $2 \%$ lidocaine with 1:100,000 epinephrine. The glycemic effect of epinephrine occurs at a plasma epinephrine concentration of 4-5 times basal levels which is at the value of $150-200 \mathrm{pg} / \mathrm{ml}^{19}$ The same concentrations may be obtained shortly after giving the injection of clinical doses of epinephrine containing local anesthesia. ${ }^{14}$ Surprisingly this study demonstrate a little decrease in the mean level of blood glucose level after giving local anesthesia with epinephrine.

The study carried out by Bortoluzzi et $\mathrm{al}^{21}$ didn't justified the changes in the blood glucose level which support our study. However the local anesthesia used by them was different $(2 \%$ mepivacaine with epinephrine). In another study same results was found in healthy as well as in diabetic patients. ${ }^{9,16} \mathrm{~A}$ higher value in the blood glucose level was found in diabetic patients by Shcaira et al. ${ }^{22}$ According to Santos-Paul et al ${ }^{23}$ there was no significant difference in the blood glucose level of diabetic patients after receiving $2 \%$ lidocaine with epinephrine which assist our study. A significant increase was revealed by Meechan et $\mathrm{al}^{24}$ during oral surgery using epinephrine. An increase in blood glucose level was also noted in those patients who were going for oral surgery using intravenous midazolam which contradict this study. ${ }^{25,17,18}$ A relevant elevation in blood glucose level was also found by Nakamura et $\mathrm{al}^{26}$ while using local anesthesia with epinephrine. A statistically significant increase was noted following administration of local anesthesia with epinephrine in diabetic patients. ${ }^{27}$ Karla et $\mathrm{al}^{20}$ revealed a significant increase in the blood glucose level while comparing diabetic with healthy patients following injection of local anesthesia with epinephrine which opposes this study. The variations in the studies might be due to differences in the patient characteristics and the method used for evaluation.

The limitation of this study is short sample size, male predominance and avoidance of anxiety reduction. However the results may clarify that the use of local anesthesia with epinephrine in diabetic patients not increases the risk of hyperglycemia. The future study may be carried out in comparison with healthy patients in different hospitals with large sample size.

\section{CONCLUSION}

This study concluded that the use of local anesthesia with 1:100,000 epinephrine have no effect on glycemic level of diabetic patient but slight lower blood glucose level was observed.

\section{CONFLICT OF INTEREST}

None to declare.

\section{REFERENCES}

1. Preshaw PM, Alba AL, Herrera D, Jepsen S, Konstantinidis A, Makrilakis K, et al. Periodontitis and diabetes: a two-way relationship. Diabetologia. 2012;55(1):21-31

2. Albandar JM. Global risk factors and risk indicators for periodontal diseases. Periodontol. 2002;9:177-206.

3. Lalla RV, D'Ambrosio JA. Dental management considerations for the patient with diabetes mellitus. JAmDentAssoc. 2001;132(10):1425-32.

4. Vijan S. In the clinic: Type 2 diabetes. Ann Intern Med. 2010;152(5):315-19.

5. Rhodus NL, Vibeto BM, Hamamoto DT. Glycemic control in patients with diabetes mellitus upon admission to a dental clinic: considerations for dental management. Quintessence Int. 2005;36(6):474-82. 
6. Barcellos IF, Halfon VLC, Oliveira LF, Barcellos Filho I. Dental conduct in a diabetic patient. Rev Bras Odontol. 2000;57(6):407-10.

7. Mariano RC, Santana SI, Coura GS. An\&aacute;lise comparativa do efeito anest\&eacute;sico da lidoca\&iacute;na $2 \%$ e da priloca\&iacute;na $3 \%$ BCl. 2000;7(27):159-65.

8. Meral G, Tasar F, Sayin F, Saysel M, Kir S, Karabulut E. Effects of lidocaine with and without epinephrine on plasma epinephrine and lidocaine concentrations and hemodynamic values during third molar surgery. Oral surgery, oral medicine, oral pathology, oral radiology, and endodontics. 2005; 100(2):e25-30.

9. Tily FE, Thomas S. Glycemic effect of administration of epinephrine-containing local anaesthesia in patients undergoing dental extraction, a comparison between healthy and diabetic patients. Int Dent J. 2007;57(2):77-83.

10. Meechan JG, Thomson CW, Blair GS, Rawlins MD. The biochemical and hemodynamic effects of adrenaline in lignocaine local anesthetic solutions in patients having third molar surgery under general anesthesia. British Journal of Oral and Maxillofacial Surgery. 1991;29:263-268.

11. Naveed A. Khawaja, Hesham Khalil, Kauser Parveen, Ahmad M. Alghamdi, et al. An influence of adrenaline $(1: 80,000)$ containing local anesthesia (2\% Xylocaine) on glycemic level of patients undergoing tooth extraction in Riyadh.Saudi Pharmaceutical Journal.2014;22(6);545-9.

12. Siddiq M, Rao S, Rai G, Hiregoudar JS, Pitale U. Study on blood glucose concentration in patients with diabetes undergoing dental extraction under local anesthesia with and without adrenaline. Journal of basic and clinical physiology and pharmacology. 2012;23(4):169-71.

13. Adelusi EA, Abiose OB, Gbolahan OO.Hemodynamic and Glycemic Safety of Two Local Anaesthetic Agents during IntraAlveolar Tooth Extraction: A Comparison. Dentistry.2020;10(2);19. doi: 10.35248/2161-1122.20.10.552

14. Vernillo AT. Diabetes mellitus: Relevance to dental treatment. Oral surgery, oral medicine, oral pathology, oral radiology, and endodontics. 2001;91(3):263-70.

15. Orso VA, Pagnoncelli RM. O perfil do paciente diab\& e a cute; tico e o tratamento odontol\&oacute;gico. Revista Odonto Ciência. 2002;17(36):206-13

16. Harvard Medical School, Harvard University. Type 2 Diabetes Mellitus. Cambridge ,MA, USA. Harvard Health Publishing.Dec, 2018. Available from: https://www.health.harvard.edu/a_to_z/type-2diabetes-mellitus-a-to-z

17. Haas DA. An update on local anesthetics in dentistry. J Can DentAssoc. 2002;68(9):546-51.

18. Levin JA, Muzyka BC, Glick M. Dental management of patients with diabetes mellitus. Compend Contin Educ Dent. 1996;17(1):82-90.

19. Malamed S. Handbook of Local Anesthesia. 6th ed. St. Louis: CV Mosby Publishing Co.; 2014.

20. Kalra P, Rana AS, Peravali RK, Gupta D, Jain G. Comparative evaluation of local anaesthesia with adrenaline and without adrenaline on blood glucose concentration in patients undergoing tooth extractions. J Maxillofac Oral Surg 2011;10:230-5.
21. Bortoluzzi MC, Manfro R, Nardi A. Glucose levels and hemodynamic changes in patients submitted to routine dental treatment with and without local anesthesia. Clinics. 2010;65(10):975-8.

22. Schaira VR, Ranali J, Saad MJ, de Oliveira PC, Ambrosano GM, Volpato MC. Influence of diazepam on blood glucose levels in nondiabetic and noninsulin-dependent diabetic subjects under dental treatment with local anesthesia. Anesth Prog. 2004;51(1):148-53.

23. Santos-Paul MA, Neves IL, Neves RS, Ramires JA. Local anesthesia with epinephrine is safe and effective for oral surgery in patients with type 2 diabetes mellitus and coronary disease: a prospective randomized study. Clinics (Sao Paulo). 2015 Mar;70(3):185-9.

24. Meechan JG. Epinephrine, magnesium, and dental local anesthetic solutions. Anesth Prog. 1996;43(4):99-102.

25. Meechan JG, Welbury RR. Metabolic responses to oral surgery under local anesthesia and sedation with intravenous midazolam: the effects of two different local anesthetics. Anesth Prog. 1992;39(12):9-12.

26. Nakamura $\mathrm{Y}$, Matsumura K, Miura K, Kurokawa $\mathrm{H}$, Abe I, Takata Y. Cardiovascular and sympathetic responses to dental surgery with local anesthesia. Hypertens Res. 2001;24(3):209-14.

27. Kaur P, Bahl R, Kaura S, Bansal S. Comparing hemodynamic and glycemic response to local anesthesia with epinephrine and without epinephrine in patients undergoing to oth extractions. Natl J Maxillofac Surg 2016;7:166-72.

DATA SHARING STATEMENT: The data that support the findings of this study are available on request from the corresponding author. The data are not publicly available due to privacy or ethical restrictions.

CONFLICT OF INTEREST: Authors declared no conflict of interest.

GRANTED SUPPORT AND FINANCIAL DISCLOSURE: Nil

\section{AUTHOR'S CONTRIBUTION}

Following authors have made substantial contributions to the manuscript as under

Khan MT, Ilyas M:

Concept and design of study, Collection of data, statistical analysis

Khan S, Kundi JA: Writing of manuscript, critical review of manuscript

Shahid: Analysis and interpretation of data, statistical analysis

Kifayat F: Data collection, bibliography

Authors agree to be accountable for all aspects of the work in ensuring that questions related to the accuracy or integrity of any part of the work are appropriately investigated and resolved. 